\title{
Lactate Dehydrogenase Activity in Gingival Crevicular Fluid as a Marker in Orthodontic Tooth Movement
}

\author{
Sarah A. Alfaqeeh ${ }^{\mathrm{a}}$ and Sukumaran Anil ${ }^{\mathrm{b}_{*}}$ \\ ${ }^{a}$ Department of Pediatric Dentistry and Orthodontics, College of Dentistry, King Saud University, Post Box: 60169, \\ Riyadh1 1545, Kingdom of Saudi Arabia \\ ${ }^{b}$ Dental Implant and Osseointegration Research Chair, Department of Periodontics and Community Dentistry, College \\ of Dentistry, King Saud University, Post Box: 60169, Riyadh11545, Kingdom of Saudi Arabia
}

\begin{abstract}
Objectives: This study aims at analyzing the changes in gingival crevicular fluid (GCF) lactate dehydrogenase (LDH) activity during orthodontic movement.

Methods: Twenty patients all requiring first premolar extractions were selected and treated with conventional straight wire mechanotherapy. Canine retraction was done using $125 \mathrm{~g}$ Nitinol closed coil springs. The maxillary canine on one side served as the experimental site while the contralateral canine served as the control. GCF was collected from the canines before initiation of retraction, then 1 hour after initiating canine retraction, followed by 1 day, 7 days, 14 days and 21 days. GCF LDH levels were estimated and compared with the control site.

Results: The results revealed significantly higher LDH levels on the $7^{\text {th }}, 14^{\text {th }}$ and $21^{\text {st }}$ day at the sites where orthodontic force had been applied. The levels also showed a significant increase from 0 hour to the $21^{\text {st }}$ day. Peak levels were seen on $14^{\text {th }}$ and $21^{\text {st }}$ day following initiation of retraction.

Conclusions: The study showed that LDH could be successfully estimated in the GCF and its increased levels could indicate active tooth movement, which could aid the clinician in monitoring active orthodontic tooth movement.
\end{abstract}

Keywords: Lactate dehydrogenase, diagnostic indicator, gingival crevicular fluid, orthodontic tooth movement, canine retraction.

\section{INTRODUCTION}

Tooth movement during orthodontic treatment is characterized by remodeling changes seen in the dental and periodontal tissues, including dental pulp, periodontal ligament, alveolar bone, and gingiva. These force-induced strains alter the vascularity and blood flow in the periodontal ligaments, resulting in local synthesis and the release of various key molecules, such as neurotransmitters, cytokines, growth factors, colony-stimulating factors, and arachidonic acid metabolites [1]. These molecules can induce several cellular responses by various cell types in and around the teeth, providing a favorable microenvironment for tissue deposition or resorption [2,3]. The biomechanical principles of tooth movement during orthodontic treatment have been extensively described $[4,5]$. These are supported by several studies that have evaluated periodontal changes subsequent to orthodontic tooth movement [6-8].

Gingival crevicular fluid (GCF) arises at the gingival margin and is otherwise termed transudate or exudate. The flow rate is related to the degree of gingival inflammation, and a rate of 0.05 to $0.20 \mu \mathrm{L}$ per minute was reported during minimal inflammation. Several studies have been performed

*Address correspondence to this author at the Department of Periodontics and Community Dentistry, College of Dentistry, King Saud University, Post Box: 60169, Riyadh11545, Saudi Arabia; Tel: +96614677434;

Mobile: +966500197223; Fax: 0096614679017;

E-mail: drsanil@gmail.com on the composition of gingival crevicular fluid and the changes seen during orthodontic tooth movement $[9,10]$.

The mechanism of bone remodeling during orthodontic treatment is associated with the release of inflammatory mediators, such as prostaglandin-E2 and interleukin 1- $\beta$ [11]. Neuropeptides such as substance $P$ and Interleukin- $1 \beta$ which are produced mainly by activated monocytes, initiate bone resorption [12, 13] either by activating osteoclasts or by stimulating the synthesis of prostaglandin-E2 [7, 14]. Force applied to a tooth is known to cause the periodontal tissues to experience either tension or compression stress, depending on the tooth movement $[15,16]$. A variety of substances involved in the bone remodeling process are diffused into the gingival crevicular fluid [1,11, 17-19]. Therefore, gingival crevicular fluid sample analysis could help in understanding the ongoing biochemical processes associated with bone turnover during orthodontic tooth movement $[6,9,11,20$ 22].

Lactate Dehydrogenase (LDH), an enzyme normally limited to the cell cytoplasm, is released extracellularly only after cell death [23]. Earlier studies have demonstrated that lactate dehydrogenase activity in gingival crevicular fluid is significantly related to gingival inflammation [24] and periodontal tissue destruction. [25]. Therefore, lactate dehydrogenase activity in the gingival crevicular fluid has been proposed as a potential marker for monitoring periodontal metabolism. Increased lactate dehydrogenase activity 
in the gingival crevicular fluid can be hypothesized during orthodontic tooth movement [3]. Earlier studies have suggested a correlation of the LDH levels in GCF during orthodontic treatment $[19,26]$.

GCF component analysis is a noninvasive method to study the cellular response of the underlying periodontal ligament during orthodontic treatment [27]. Limited data is currently available on GCF LDH and warrants further research to establish a sensitive marker which can be used as a noninvasive chair-side test. Hence, the present study has been undertaken to assess the LDH levels in the crevicular fluid of patients undergoing orthodontic treatment.

\section{MATERIALS AND METHODS}

\section{Study Population}

A sample of 20 subjects (10 males and 10 females), age range 15 to 25 years, requiring orthodontic treatment was taken for this study. All subjects had Angle's Class I malocclusion with bimaxillary dentoalveolar protrusion and proclination with minimal or no crowding. They all required extraction of all the four first premolar teeth as part of their orthodontic treatment. Treatment plan constituted fixed orthodontic therapy with extraction of the first bicuspids, followed by individual canine retraction, and maximum anchorage conservation, space closure, finishing and detailing and a fixed lingual retainer. The protocol of this study was reviewed and formally approved by the Ethical Committee at the College of Dentistry, King Saud University, Riyadh. Informed consent was also obtained from each subject, after explaining the nature of the study.

The subjects selected had neither oral nor systemic diseases, had no periodontal pockets, and had not been on any antibiotic therapy for at least three months prior to the commencement of the study. The subjects were agreed to strictly adhere to the investigator's instructions on oral hygiene and were willing to follow the prescribed oral hygiene program and orthodontic treatment.

\section{Orthodontic Treatment}

All patients were treated with conventional straight wire (0.022 x 0.028) mechanotherapy (Discovery ${ }^{\circledR}$ brackets, Dentaurum, Ispringen, Germany). After leveling and alignment, the retraction of the canine was initiated on a base wire of 0.019 x 0.025" Stainless Steel preformed standard arch shape (Arch wires ${ }^{\circledR}, 3 \mathrm{M}$ Unitek, Monrovia, California, USA). Canine retraction was performed, on one side randomly chosen using Nitinol closed coil spring $(9 \mathrm{~mm})$ exerting $125 \mathrm{~g}$ of constant force (Nitinol closed coil spring ${ }^{\circledR}$, 3M Unitek, Monrovia, California, USA). The canine on the opposite side, served as the control and no orthodontic force was applied.

\section{Periodontal Examination}

Scaling was done two weeks prior to sample collection. All patients complied with strict oral hygiene instructions to rinse twice daily with 0.5 ounces $\mathrm{ml}$ of $0.2 \%$ chlorhexidine gluconate throughout the study period and to brush their teeth at least two times a day using a tooth brush and tooth paste. Periodic recall were performed to evaluate oral hy- giene levels. Patients were instructed to avoid all medications or drugs including nonsteroidal antiinflammatory drugs during the study period. Subjects who strictly adhered to the oral hygiene regime were included in the study, after preliminarily monitoring the patients for six weeks prior to the treatment. The periodontal condition was periodically assessed throughout the study period, by monitoring the plaque and gingival bleeding.

\section{Gingival Crevicular Fluid Collection}

Gingival crevicular fluid (GCF) samples were collected using the method employed by Lamster et al. [28]. The individual crevicular sites were isolated with cotton rolls and gently air dried. Then six pre-cut methylcellulose filter periopaper strips ${ }^{\circledR}$ were inserted into the crevice at the mesiolabial line angle, mid-labial surface, disto-labial line angle, disto-palatal line angle, mid-palatal surface and mesiopalatal line angle until mild resistance was felt. These were left in place for 60 seconds in continued isolation. Next, the six strips were immediately placed in individual sealed plastic tubes (Cryotube ${ }^{\circledR}, 2.0 \mathrm{~mL}$, NUNC, Roskilde, Denmark) and snap frozen at $-80^{\circ} \mathrm{C}$ until further processing was performed.

The gingival crevicular fluid was collected by periopaper strips (Periopaper strips ${ }^{\circledR}$, ProFlow Inc., Amityville, NY, USA) from the maxillary canines prior to canine retraction, after initiating canine retraction, 1 hour , 1 day , 7 days , 14 days and 21 days.

\section{GCF Lactate Dehydrogenase Assay}

The gingival crevicular fluid lactate dehydrogenase activity was spectrophotometrically determined [24]. The paper strips were incubated for 5 minutes in a substrate of 16.2 $\mathrm{mmol} / \mathrm{L}$ pyruvate, $0.194 \mathrm{mmol} / \mathrm{L}$ reduced nicotinamide adenine dinucleotide (NADH), $54.0 \mathrm{mmol} / \mathrm{L}$ phosphate buffer $\left(\mathrm{pH} 7.5 \pm 0.1\right.$ at $\left.30^{\circ} \mathrm{C}\right)$, in a total volume of $1.0 \mathrm{ml}$. In the presence of lactate dehydrogenase, pyruvate is reduced to Llactate with the simultaneous oxidation of NADH. The rate of decrease in absorbance at $340 \mathrm{~nm}$, representing the NADH consumed, is directly proportionate to the lactate dehydrogenase activity in the sample. For the $1 \mathrm{~cm}$ path length used, a value of 6.22 was considered as the NADH millimolar absorptivity. Results were first converted into enzyme activity units ( 1 unit $=1 \mu \mathrm{mol}$ of $\mathrm{NAD}^{+}$released per minute at $30^{\circ} \mathrm{C}$ ) and finally expressed as total lactate dehydrogenase activity ( $\mu$ mol units/L) per sample.

\section{Statistical Analyses}

All statistical analyses were performed with $\mathrm{GraphPad}^{\circledR}$ Instat 3.05 software (GraphPad Software Inc, San Diego, CA, USA). LDH levels at different time intervals were compared and analyzed using ANOVA. We used a 95\% confidence interval assuming that there was a significant difference when the P-value was found to be less than 0.05 .

\section{RESULTS}

The gingival crevicular fluid lactate dehydrogenase level is shown in Fig. (1). In the control site the LDH levels varied from 96.05 at 0 hour to 119.50 on the $21^{\text {st }}$ day. At the experimental site where tooth movement occurred, signifi- 


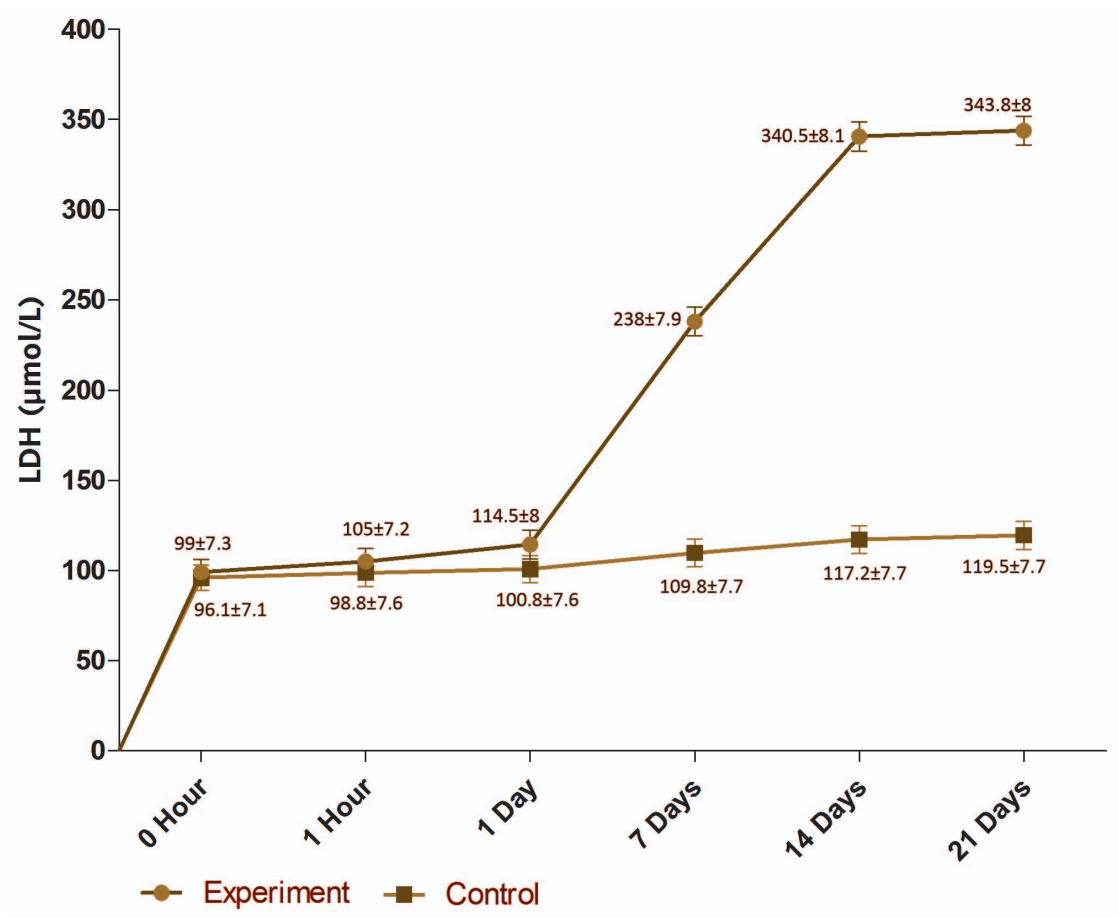

Fig. (1). Gingival crevicular fluid lactate dehydrogenase level $(\mu \mathrm{mol} / \mathrm{L})$ in the control and experiment sites (values are mean \pm SEM).

cantly higher LDH levels from the $7^{\text {th }}$ day onwards until $21^{\text {st }}$ day were noted. The lactate dehydrogenase level increased with time in the experiment site from 0 hour to 21 days; from $99.00 \pm 32.47$ to $343.75 \pm 35.76 \mu \mathrm{mol} / \mathrm{L}$. Using the nonparametric Friedman test for several related samples to test for any statistical significant difference within either the control or experiment site at different points in time, a statistically significant difference was found only in the experiment site from 7, 14 and 21 days.

\section{DISCUSSION}

The bone remodeling that occurs during orthodontic tooth movement is a biologic process involving an acute inflammatory response in the periodontal tissues. The sequence characterized by periods of activation, resorption, reversal, and formation has been recently described as occurring in both tension and compression tooth sites during orthodontic tooth movement [29]. In Orthodontics, mechanical stress appears to evoke biochemical and structural responses in a variety of cell types in vivo as well as in vitro [11,30, 31]. The early phase of orthodontic tooth movement involves an acute inflammatory response, distinguished by periodontal vasodilation and leukocyte migration from the periodontal ligament capillaries [3]. The mechanism of bone resorption could also be related to the release of inflammatory mediators found in the gingival crevicular fluid [11].

Orthodontic tooth movement induces a biological process leading to bone resorption in the pressure sites and bone deposition in tension sites $[16,32]$. Histological studies showed that first a wave of resorption occurred in 3 to 5 days followed by its reversal in 5 to 7 days. This is followed by a late wave of bone formation between 7 and 14 days [33, 34].

Lactate dehydrogenase, an enzyme normally limited to the cytoplasm of cells, which is released extracellularly only after cell death, is related to cell necrosis and tissue break- down. Studies have demonstrated that the LDH activity in gingival crevicular fluid is significantly related to gingival inflammation and tissue destruction $[24,35]$ Therefore, lactate dehydrogenase activity in the gingival crevicular fluid has been recognized as a potential marker for monitoring periodontal metabolism [25].

Lactate dehydrogenase identified as a tissue destruction indicator, signals an increase in LDH during orthodontic tooth movement due to changes in the periodontal ligament $[16,25]$. Currently, only a few studies have explored the gingival crevicular fluid LDH levels during orthodontic tooth movement $[19,26]$. These studies have revealed promising results and indicated that the gingival crevicular fluid levels of lactate dehydrogenase could reflect the biologic activity in the periodontium during orthodontic tooth movement.

The observations of this study showed increased LDH levels at the site where orthodontic force was applied compared to the contralateral control site. The lactate dehydrogenase levels showed a steady increase with time i.e. from 0 day to 21 days. The significant increase in the gingival crevicular fluid lactate dehydrogenase activity at the test site concurs with the earlier reports $[19,26]$, although the present study does not distinguish between compression and tension sites.

Reitan [15] described three distinct processes in periodontal tissue by orthodontic forces. The first is characterized by tissue deformation. In the second phase, the appropriate cells establish a microenvironment that allows for correct tissue modeling and remodeling. The last phase represents tissue turnover, to allow a reduction in the applied strain, which terminates in appliance deactivation. This increase in the lactate dehydrogenase during orthodontic treatment is attributed to periodontal changes such as tissue resorption or destruction $[34,36]$. In the periodontal ligament, hyaliniza- 
tion of the most compressed area induced by compressive forces has been reported [3]. This hyaline zone is described as an area of focal aseptic necrosis [16] persisting in the pressure zone, that resists degradation, depending on the magnitude of the force [15] that resists degradation, persists in the pressure zone, and depends on the magnitude of the force [15]. A study conducted on a rat model showed cytoplasmic enzymes such as lactate dehydrogenase in this extracellular environment [36].

This study revealed that lactate dehydrogenase enzyme activity could be successfully estimated in the gingival crevicular fluid. The gingival crevicular fluid lactate dehydrogenase enzyme showed a steady increase during orthodontic tooth movement with a statistically significant increase on the $7^{\text {th }}, 14^{\text {th }}$ and $21^{\text {st }}$ days compared with the control site as well, with the initiation of the tooth movement. From the observations made in this study, it can be concluded that an estimation of gingival crevicular fluid LDH levels can be used as an indicator to monitor active orthodontic tooth movement. Further research and new techniques may assist in developing more sensitive and reliable markers that can be used as chairside test in orthodontic practice.

\section{SOURCES OF SUPPORT IN THE FORM OF GRANTS}

The study was supported by a grant from the College of Dentistry Research Center, King Saud University, Riyadh.

\section{REFERENCES}

[1] Kavadia-Tsatala S, Kaklamanos EG, Tsalikis L. Effects of orthodontic treatment on gingival crevicular fluid flow rate and composition: clinical implications and applications. Int J Adult Orthodon Orthognath Surg 2002; 17: 191-205.

[2] Davidovitch Z. Tooth movement. Crit Rev Oral Biol Med 1991; 2: 411-50.

[3] Davidovitch Z, Nicolay OF, Ngan PW, Shanfeld JL. Neurotransmitters, cytokines, and the control of alveolar bone remodeling in orthodontics. Dent Clin North Am 1988; 32: 411-35.

[4] Krishnan V, Davidovitch Z. Cellular, molecular, and tissue-level reactions to orthodontic force. Am J Orthod Dentofacial Orthop 2006; 129: e461-9.

[5] Sandy JR, Farndale RW, Meikle MC. Recent advances in understanding mechanically induced bone remodeling and their relevance to orthodontic theory and practice. Am J Orthod Dentofacial Orthop 1993; 103: 212-22.

[6] Lowney JJ, Norton LA, Shafer DM, Rossomando EF. Orthodontic forces increase tumor necrosis factor alpha in the human gingival sulcus. Am J Orthod Dentofacial Orthop 1995; 108: 519-24.

[7] Saito M, Saito S, Ngan PW, et al. Interleukin 1 beta and prostaglandin $\mathrm{E}$ are involved in the response of periodontal cells to mechanical stress in vivo and in vitro. Am J Orthod Dentofacial Orthop 1991; 99: 226-40.

[8] Yamaguchi M, Yoshii M, Kasai K. Relationship between substance $\mathrm{P}$ and interleukin-1beta in gingival crevicular fluid during orthodontic tooth movement in adults. Eur J Orthod 2006; 28: 2416.

[9] Griffiths GS, Moulson AM, Petrie A, James IT. Evaluation of osteocalcin and pyridinium crosslinks of bone collagen as markers of bone turnover in gingival crevicular fluid during different stages of orthodontic treatment. J Clin Periodontol 1998; 25: 492-8.

[10] Iwasaki LR, Haack JE, Nickel JC, et al. Human interleukin-1 beta and interleukin-1 receptor antagonist secretion and velocity of tooth movement. Arch Oral Biol 2001; 46: 185-9.

[11] Uematsu S, Mogi M, Deguchi T. Interleukin (IL)-1 beta, IL-6, tumor necrosis factor-alpha, epidermal growth factor, and beta 2 microglobulin levels are elevated in gingival crevicular fluid during human orthodontic tooth movement. J Dent Res 1996; 75: 562-7.
[12] Giannopoulou C, Mombelli A, Tsinidou K, et al. Detection of gingival crevicular fluid cytokines in children and adolescents with and without fixed orthodontic appliances. Acta Odontol Scand 2008; 66: 169-73.

[13] Cantarella G, Cantarella R, Caltabiano M, et al. Levels of matrix metalloproteinases 1 and 2 in human gingival crevicular fluid during initial tooth movement. Am J Orthod Dentofacial Orthop 2006; 130: 568 e511-566.

[14] Saito S, Ngan P, Saito M, et al. Interactive effects between cytokines on PGE production by human periodontal ligament fibroblasts in vitro. J Dent Res1990; 69: 1456-62.

[15] Reitan K. Clinical and histologic observations on tooth movement during and after orthodontic treatment. Am J Orthod 1967; 53: 72145.

[16] Rygh P. Ultrastructural changes in tension zones of rat molar periodontium incident to orthodontic tooth movement. Am J Orthod 1976; 70: 269-81.

[17] Dilsiz A, Kilic N, Aydin T, et al. Leptin levels in gingival crevicular fluid during orthodontic tooth movement. Angle Orthod 2010; 80: 504-8.

[18] Perinetti G, Paolantonio M, Serra E, et al. Longitudinal monitoring of subgingival colonization by Actinobacillus actinomycetemcomitans, and crevicular alkaline phosphatase and aspartate aminotransferase activities around orthodontically treated teeth. J Clin Periodontol 2004; 31: 60-7.

[19] Perinetti G, Serra E, Paolantonio M, et al. Lactate dehydrogenase activity in human gingival crevicular fluid during orthodontic treatment: a controlled, short-term longitudinal study. J Periodontol 2005; 76: 411-7.

[20] Grieve WG 3rd, Johnson GK, Moore RN, et al. Prostaglandin E (PGE) and interleukin-1 beta (IL-1 beta) levels in gingival crevicular fluid during human orthodontic tooth movement. Am J Orthod Dentofacial Orthop 1994; 105: 369-74.

[21] Uematsu S, Mogi M, Deguchi T. Increase of transforming growth factor-beta 1 in gingival crevicular fluid during human orthodontic tooth movement. Arch Oral Biol 1996; 41: 1091-5.

[22] Last KS, Donkin C, Embery G. Glycosaminoglycans in human gingival crevicular fluid during orthodontic movement. Arch Oral Biol 1988; 33: 907-12.

[23] Williams DL, Marks V. Principles of clinical biochemistry : scientific foundations. Oxford [England]: Heinemann Medical Books 1988.

[24] Lamster IB, Mandella RD, Gordon JM. Lactate dehydrogenase activity in gingival crevicular fluid collected with filter paper strips: analysis in subjects with non-inflamed and mildly inflamed gingiva. J Clin Periodontol 1985; 12: 153-61.

[25] Atici K, Yamalik N, Eratalay K, Etikan I. Analysis of gingival crevicular fluid intracytoplasmic enzyme activity in patients with adult periodontitis and rapidly progressive periodontitis: a longitudinal study model with periodontal treatment. J Periodontol 1998; 69: 1155-63.

[26] Serra E, Perinetti G, D'Attilio M, et al. Lactate dehydrogenase activity in gingival crevicular fluid during orthodontic treatment. Am J Orthod Dentofacial Orthop 2003; 124: 206-11.

[27] Ren Y, Maltha JC, Van't Hof MA, et al. Cytokine levels in crevicular fluid are less responsive to orthodontic force in adults than in juveniles. J Clin Periodontol 2002; 29: 757-62.

[28] Lamster IB, Hartley LJ, Vogel RI. Development of a biochemical profile for gingival crevicular fluid. Methodological considerations and evaluation of collagen-degrading and ground substancedegrading enzyme activity during experimental gingivitis. J Periodontol 1985; 56: 13-21.

[29] Wise GE, King GJ. Mechanisms of tooth eruption and orthodontic tooth movement. J Dent Res 2008; 87: 414-34.

[30] Roberts WE, Chase DC. Kinetics of cell proliferation and migration associated with orthodontically-induced osteogenesis. J Dent Res 1981; 60: 174-81.

[31] Perinetti G, Paolantonio M, D'Attilio M, et al. Alkaline phosphatase activity in gingival crevicular fluid during human orthodontic tooth movement. Am J Orthod Dentofacial Orthop 2002; 122: 548-56.

[32] Storey E. The nature of tooth movement. Am J Orthod 1973; 63: 292-314. 
[33] Keeling S KG, Valdez M. Serum and alveolar bone phosphatase changes reflect remodeling during orthodontic tooth movement. Am J Orthod Dentofacial Orthop 1992; 103: 320-6.

[34] King GJ, Keeling SD, Wronski TJ. Histomorphometric study of alveolar bone turnover in orthodontic tooth movement. Bone 1991; 12: 401-9.
[35] Lamster IB, Vogel RI, Hartley LJ, et al. Lactate dehydrogenase, beta-glucuronidase and arylsulfatase activity in gingival crevicular fluid associated with experimental gingivitis in man. J Periodontol 1985; 56: 139-47.

[36] Lilja E, Lindskog S, Hammarstrom L. Histochemistry of enzymes associated with tissue degradation incident to orthodontic tooth movement. Am J Orthod 1983; 83: 62-75.

Received: January 20, 2011

(C) Alfaqeeh and Anil; Licensee Bentham Open.

This is an open access article licensed under the terms of the Creative Commons Attribution Non-Commercial License (http://creativecommons.org/licenses/by-nc/3.0/) which permits unrestricted, non-commercial use, distribution and reproduction in any medium, provided the work is properly cited. 